\title{
THE EFFECT OF INFORMATION SEEKING BEHAVIOR ON ONLINE DATABASE USAGE AMONG THE UNDERGRADUATE STUDENTS
}

\author{
Z. ZULKIFLI ${ }^{1 \mathrm{a}}$, E. SALWANA ${ }^{2 \mathrm{~b}}$, A. A. SALAHUDDIN ${ }^{1 \mathrm{c}}$, N. H. M. DAUD ${ }^{1 \mathrm{a}}$ \\ ${ }^{1}$ Kulliyyah of Information and Communication Technology, International Islamic University Malaysia \\ P.O. Box 10, 50728 Kuala Lumpur, Malaysia \\ ${ }^{2}$ Institute of Visual Informatics, Universiti Kebangsaan Malaysia, 43600 Bangi, Selangor, Malaysia \\ a E-mail: Phone: +603 6196 6426, Fax: +603 6196 5179, E-mail: zahidahz@iium.edu.my (Corresponding author) \\ b E-mail: Phone: +603 8921 7171, Fax: +603 8921 6072, E-mail: elysalwana@ukm.edu.my \\ c E-mail: Phone: +603 6196 6426, Fax: +603 6196 5179, E-mail: ashraf.iium.ali@gmail.com
}

\begin{abstract}
Every year the library of IIUM subscribes to quite a number of online databases with huge expenses but the utilization of these databases is countable. 10 out of 53 subscriptions have been terminated by 2015 to save the cost go in vain. The purpose of this paper is to develop a model based on the ISB elements to identify the reason behind this low usage and to increase the usage of online databases in the future. It has undertaken a quantitative approach to identify the elements of ISB among undergraduate (UG) students. The primary data has been collected through questionnaires based on the variables identified in the objective. There are 118 samples participating in this research and the proposed model has been adapted from Savolainen and Wilson. Psychological perception, searching strategies and the information resources have been considered as the independent variable and measured the usage of the online database among UG students as the dependent variable. The results have shown that there are seven elements which have an influence on the usage of the online database among IIUM UG students. Despite the limited number of samples and a specific group of students, the proposed model can enhance the usage of online database system subscribed to by IIUM library and a search engine can be developed to get the usage increased. In that sense, it is recommended to involve more participants from the different levels of students and users to get diverse elements of ISB. However, the paper contributes to bridging the gap between the online database usage and the users, believed to have an effective outcome for online database subscription. It is hoped that the proposed model would significantly fill this gap and help the library to increase the number of users for their expensive databases.
\end{abstract}

Keywords: information seeking behavior, information behavior, online database, model development

\section{Introduction}

ISB is known as information seeking behavior, categorized as one of the sub-disciplines of Library and Information Science (LIS). It defines what the need of people is, how they seek, manage, give and use the information in different perspectives [1]. According to Wilson [2], ISB is how people behave when interacting with systems such as online databases. Besides, it also encompasses the interaction of people with information processing and use.

\section{Background of problems}

Information can be resourceful and efficient, especially in academic aspect through the study of ISB. Comprehensive understanding, characterization, and iden- tification of ISB assists people to find appropriate information that they need.

This study focuses on ISB among UG students towards the usage of online databases subscribed specifically in International Islamic University Malaysia (IIUM). Online databases contain only authentic and evaluated information from published works such as academic journals. Besides, the information gets updated frequently and published by the experts, which makes it reliable and very beneficial for the students.

IIUM library subscribed several online databases which is being accessed by around 15,625 undergraduate (UG) students. However, up to the year 2015, 10 out of 53 online databases terminated from the subscription due to the decreasing and underutilized usage.

Open Acces statement. This is an open-access article distributed under the terms of the Creative Commons AttributionNonCommercial 4.0 International License (https://creativecommons.org/licenses/by-nc/4.0/), which permits unrestricted use, distribution, and reproduction in any medium for non-commercial purposes, provided the original author and source are credited, a link to the CC License is provided, and changes - if any - are indicated. 
The awareness of IIUM undergraduate students towards the usage of online database provided by IIUM library is explored through this study since a model of relationship between ISB and the usage of online database has been developed based on the result. The paper has been organized in several sections. Starting from objectives and research questions, it has stated the view point of previous research about ISB in section five; methodology and analysis has been elaborated in section six and seven. Section eight has discussed about the findings in details and nine has concluded the paper.

\section{Research objectives}

The study aimed to achieve its findings following the objectives below. The objectives contain the three main elements of ISB.

1. To investigate the elements of ISB among IIUM UG students when using online database subscribed to by IIUM library.

2. To discover the relationship between elements of ISB among IIUM UG student and the usage of online database.

3. To develop a model based on the ISB elements of IIUM UG student and the usage of online database.

\section{Research questions}

Following the objectives and the problem statement above, the study has developed three research questions mainly to ordinate its methodology and accomplish its objectives.

1. What are the elements of ISB among IIUM undergraduate students?

2. How the elements of ISB among undergraduate students influence the usage of online database?

3. How to construct ISB model among IIUM undergraduate students on the usage of online database?

\section{Literature review}

This section discusses on the ISB which started by discussing the concept of ISB followed by the previous study related to ISB among undergraduate students.

\subsection{Information seeking behavior}

ISB can be defined as a purposive behavior of user to find useful information using systems [3]. Besides, the urge of information needs to gain the knowledge resulted in the behavior of information search. The medium of information searching is through automated technologies such as World Wide Web and online da-

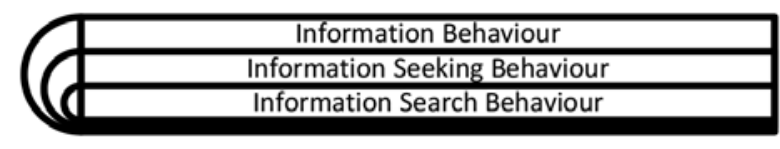

Fig. 1. Wilson's nested model (Wilson, 2000)

tabase [2]. Figure 1 shows the Wilson's nested model [2] to explain the field of information search.

Wilson [2] defines information behavior as the total of human behavior that relates to sources and channels of information. ISB is the subset of information seeking behavior. Wilson's nested model consists of all the interactions with the system that includes hu man computer interaction level such as the use of the mouse and clicks on links, and intellectual level such as adopting a Boolean search strategy or determining the criteria for deciding which of two books selected from adjacent places on a library shelf is most useful. Besides, ISB involves mental acts, such as judging the relevance of data or information retrieved.

Xie [3] mentions that information searching behavior is related to the information retrieval where the strategy to search and information collection are included. Xie characterized it into several levels that include tactics such as user method when searching information in system, strategies and usage patterns; query formulation and reformulation based on analysis of transaction logs submitted to search engines.

Therefore, ISB is the behavior of users to search the information needed through the automated technologies such as online database. The behavior can be narrowed to the user method and strategy when searching the information.

\subsection{Previous research related to ISB among students}

Education required the students to search and gather information related as much as possible to study a course. Pal \& Poyen [4] have discussed information as a source of solving problems. The urge of searching information among students is normal in order to solve the problems in academic or to complete any tasks given by the lecturer as cited by Hjørland [5].

Shakeel \& Vinayagamoorthy [6] conducted a study of ISB among students at Business School in Academic City, Dubai. They find out that the student always looks for the sources or channels that are time and cost effective and allows them to quickly copy paste the information and easily do the printing.

A case study at University of the Punjab by Malik [7] identified the criteria of search engines that will attract the student to use it. Table 1 below shows the frequency and percentage features of search engine that include ease of use, relevance, reliability, speed, accuracy, familiarity, easy interface, language, durability and currency by the student at University of the 
Table 1. Frequency and Percentage of Search Engine Features (Goel \& Yadav, 2012 \& Malik, 2009)

\begin{tabular}{lcc}
\hline Features of search engine & Frequency & Percent \\
\hline Ease of use & 144 & 72.0 \\
Relevancy & 120 & 60.0 \\
Reliability & 113 & 56.5 \\
Speed & 107 & 53.5 \\
Accuracy & 98 & 49.0 \\
Familiarity & 91 & 45.5 \\
Easy interface & 71 & 35.5 \\
Language & 73 & 36.5 \\
Durability & 32 & 16.0 \\
Currency & 25 & 12.5 \\
\hline
\end{tabular}

Punjab. The top criteria of search engines are ease of use, relevancy and reliability.

Therefore, previous studies show that the search strategies, demographic information and ease of use are highly important aspects for the students. Besides, the appearance of system is important too in order to attract the student to use online database provided by the university [3, 6-8].

\subsection{Conception of online database usage}

\subsubsection{Online}

Database can be described as the repository for data and it can be used for any bookkeeping activity while online database is connected to networks and contains the collection of computerized information or data such as articles that enable users to search it online. Bhatt states that the online database is also a scholarly source where the information is stored updated and latest [9].

Information seeking behavior is closely related to online database since it is defined as the act of seeking information through any system such as online database to gain information needed. Besides, online database is one of Information Retrieval (IR) systems where IR means to find sources that satisfy information needs from a very large collection of data stored in computers.

In order to search documents, search strategies and techniques are important to apply in information retrieval process. Unfortunately, many users have huge problems with search strategies using terms and keywords [10].

Thus, the purpose of online databases is to facilitate the student since they can find all the authentic information in the databases. However, the students should have the knowledge of search strategies in order to retrieve the information from databases.
5.3.2. Previous research related to online database usage among students

Knowledge has been stored in libraries before the existence of online database. Nowadays, students can easily acquire the knowledge with various topics in online databases.

A study conducted in Ankara University by [11] shows that the online database is occasionally used by $52 \%$ among the respondents in the university. The results in their study show that the most top reason is because the respondent does not know how to use online databases provided. Other reasons of not using online databases provided are because the respondent met the information needed in other resources and the respondent has no knowledge about online databases.

The monthly access of online databases in the study conducted in two research universities, 1) University of Michigan and 2) Carnegie Foundation for the Advancement Teaching by Mbabu et al. [12] shows that the usage of online databases provided is less than $50 \%$ for four months. The study also finds that freshman uses of online database provided the most compared to other classes standing with $56 \%$.

Azoulay-Shwartz \& Ilani [13] find out that students face difficulties to use online database effectively on the aspects of 1) searching, 2) understanding the meaning of information acquired and 3) how to process the information acquired. The inabilities will affect the usage of online databases among students in universities.

Therefore, these studies show that online database utilization can be affected by the difficulties in dealing with the online database provided by the universities.

\subsection{Integration of theories and models to develop a theoretical framework}

\subsubsection{Relevant theories}

Human interaction and the method of seeking and utilizing information acquired is known as information behavior [14]. The behavior of information search hence can be defined as the act of how humans search information through information retrieval technology or system such as online database. The search query is usually affected by search behavior [15]. Various information can be retrieved through a single search in the system. Therefore, the theory of having sufficient skills and strategies to search information needed is relevant to this study.

According to Sriram, one of the most important parts of electronic database is the resources which influence the organization and organization behavior. 


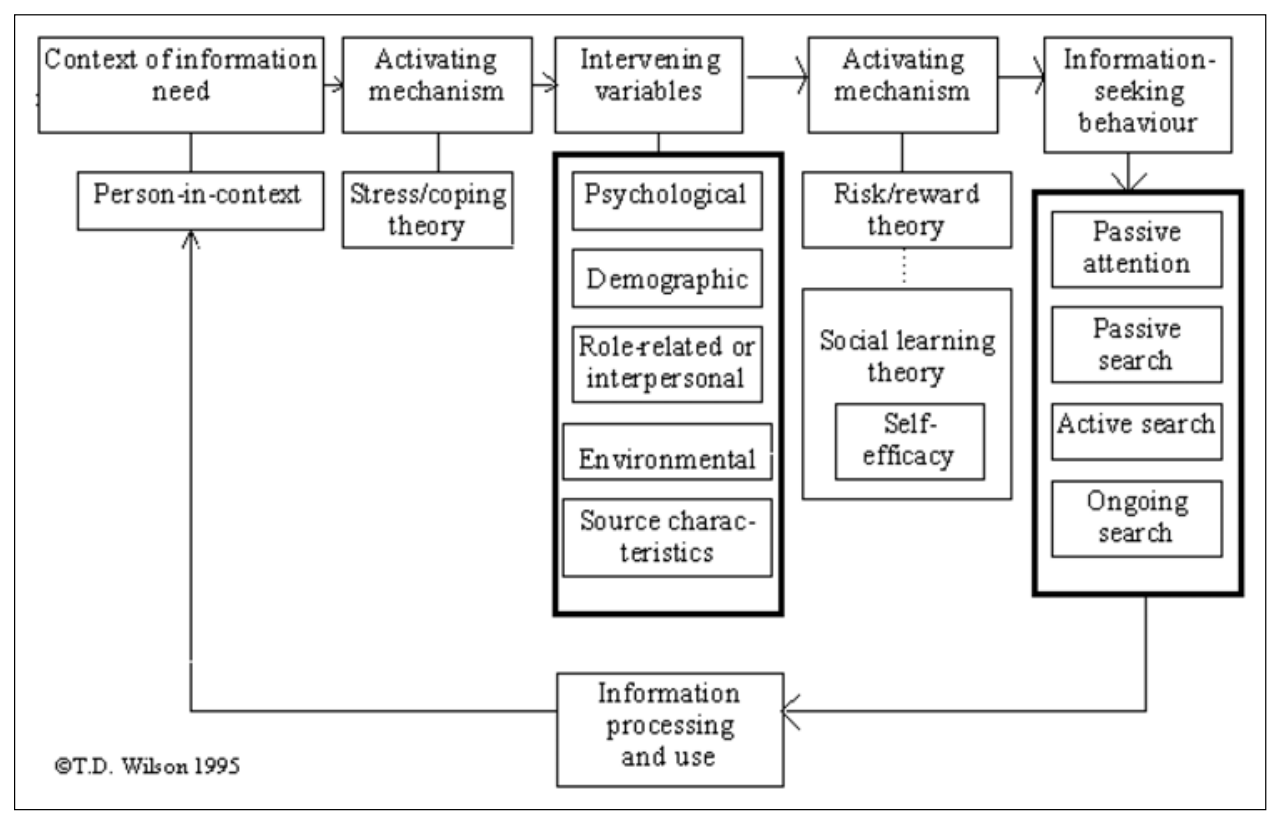

Fig. 2. Wilson model of information need and seeking (Wilson, 2007)

He stated, "resources have their own characteristics to influence the users to utilize them to their full potentials" [16]. Therefore, resources can be one of the factors influencing information searching behavior among undergraduate students in IIUM. Accordingly, the relevant models related to the theories of Hoffman have been reviewed to construct the research framework below.

\subsubsection{Relevant models}

The relevant models chosen are Information Need and Seeking Model by Wilson [17], Information Seeking
Behavior Model by Niu \& Hemminger [18], and Saracevic Model of Information Retrieval [19]. The models are discussed next in detail.

\subsubsection{Wilson model}

Wilson model shown in Fig. 2 is the evolution of Wilson's general model where the intervening variables and information seeking behavior are identified. The variables identified are psychological, demographic, role-related, environmental and source characteristic.

The behavior of the seeker is observed and divided into four types which are passive attention,

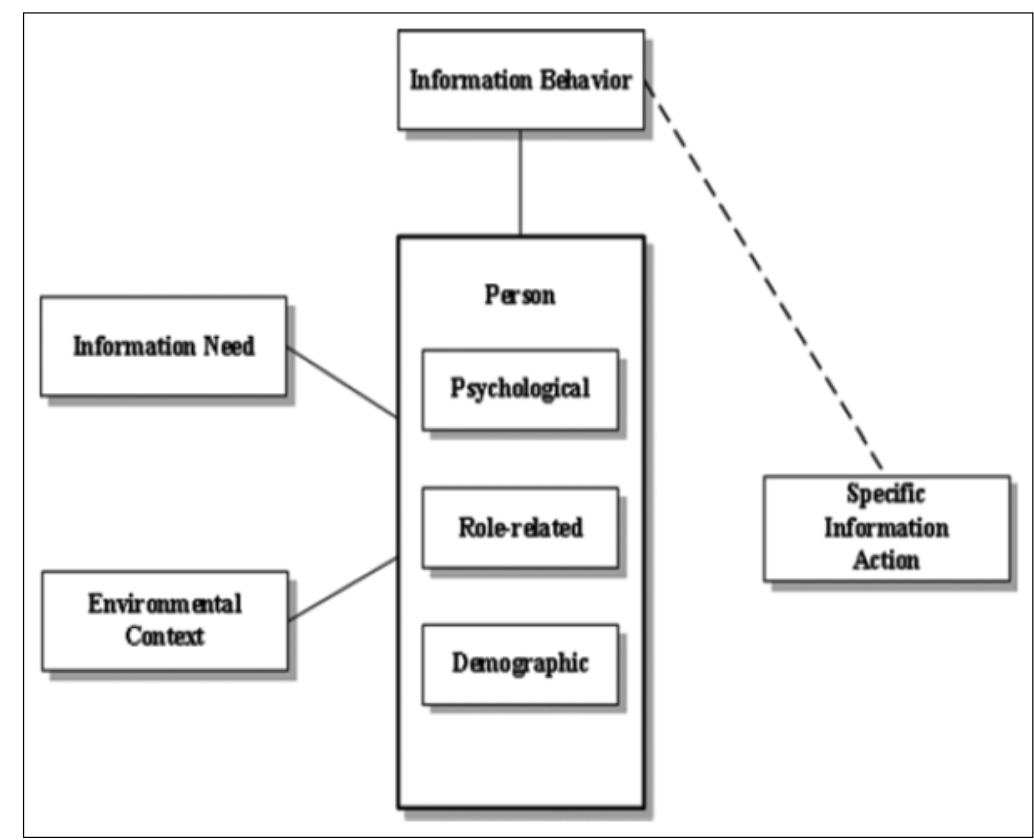

Fig. 3. Niu \& Hemminger model of information seeking behavior (Niu \& Hemminger, 2012) 


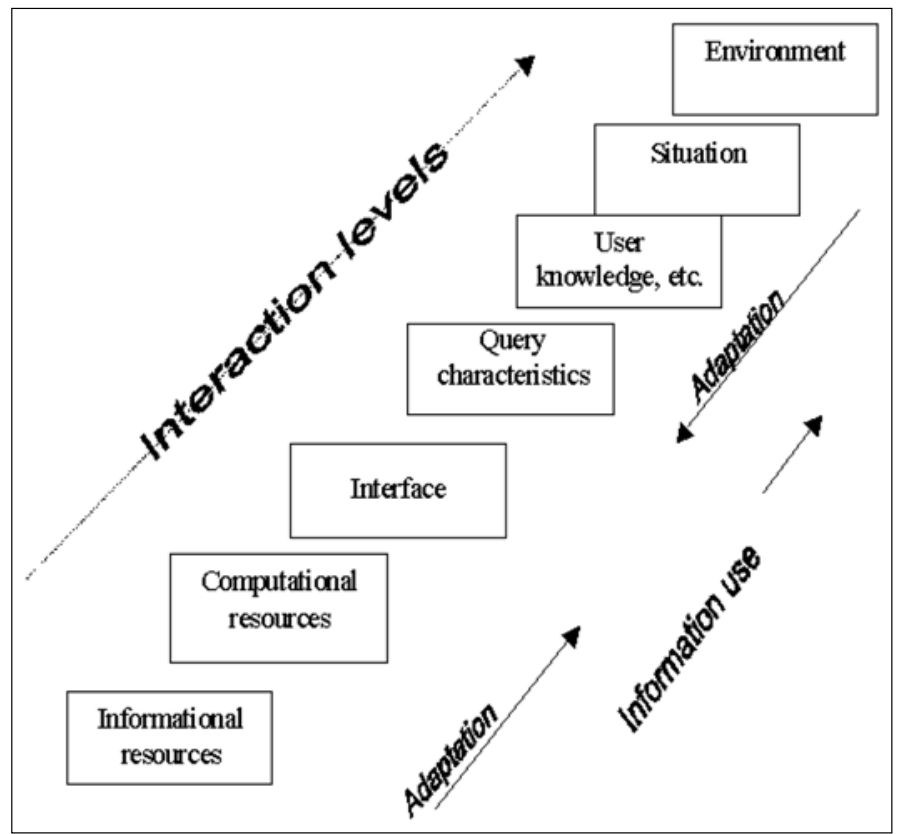

Fig. 4. Information retrieval process model by Saracevic (Wilson, 1966)

passive search, active search and ongoing search. The information seeking behavior will affect the process and use of information, and the user's need of information as shown in the loop of the model below.

Besides, this model can be useful to system designers as well since the activating mechanism element is included. As a result, any information retrieval systems designed will have less risk of failure and the user's sense of self-efficacy is increased if the designer understands the theory of risk/reward stated in the model.

However, for this study, the intervening variables of psychological, demographic, role-related, environmental and source characteristics in the Wilson Model will be adapted for IIUM undergraduate ISB perspective.

\subsubsection{Niu \& Hemminger model}

The model of Niu and Hemminger as shown in Fig. 3 is adapted from Wilson's revised general model and Buente \& Robin's model of everyday life information practices [18].

The specific information action is determined by the combination of the attributes of the person, information need and the environmental context. The attributes of the person are psychological, role-related and demographic. Specific information action is the dependent variable in this model. Other elements are treated as the predictor. Thus, the person attributes, environmental context and information need will be adapted to develop the model of ISB in this study as the variables.

\subsubsection{Saracevic model}

Saracevic model shown in Fig. 4 consists of three levels of structures which are; surface, cognitive and situational [20].

At the surface level, the user interacts with the system through the interface by issuing the queries and the system responds to the user. At the cognitive level, the user interacts with the output of the system that related to the initial problem. Lastly, at the situational level, the user will interact with problem and resulting the information need. The elements of resources, search strategies (query characteristics), user knowledge and the environment will be adapted for this study.

\subsubsection{Theoretical framework}

The theoretical framework is an important element to determine the existing theories related to the top-

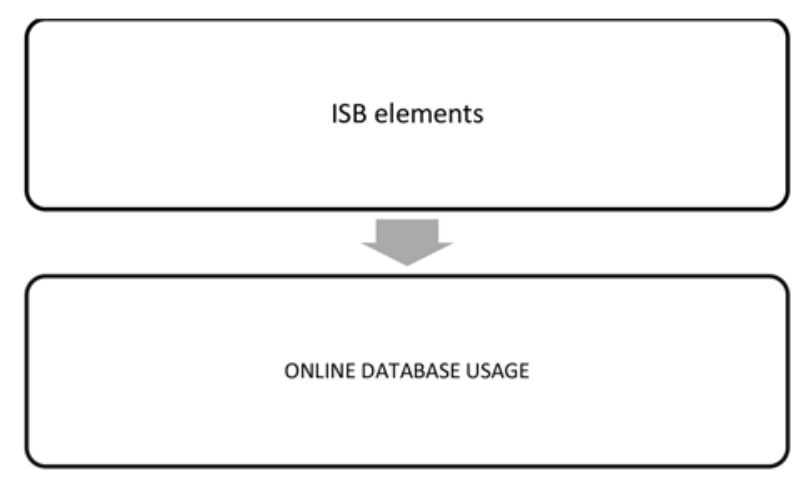

Fig. 5. ISB and the influence of online database usage 
ic of research after the problem statement and research question are identified. A good theoretical framework shows the research is based on established theories and facts obtained from a reliable study [21].

This study involves the elements of information seeking behavior (ISB) that will influence the usage of online database in IIUM. Figure 5 shows the general relationship between ISB elements and online database usage.

The elements of ISB are adapted from the theories and models discussed previously [1, 2]. Independent variables consist of psychological perception, searching strategies and the information resources provided by IIUM library. The dependent variable for this study will be the online database usage. Thus, the proposed theoretical framework is shown in Fig. 6.

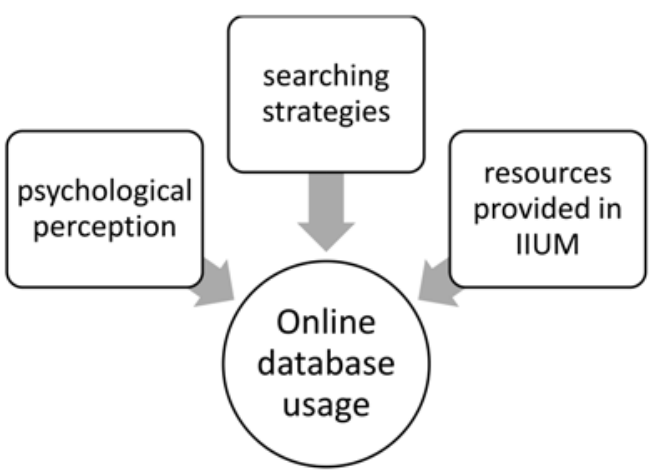

Fig. 6. Proposed Theoretical Framework Adapted from Previous Studies (Savolainen, 2007; Wilson, 2000)

There will be three hypotheses based on the proposed framework as follows: psychological perception is proposed to predict the usage of online database, searching strategies are proposed to predict the online database usage and lastly, resources provided are proposed to predict online database usage. The three hypotheses in this study as below will be tested using correlation in SPSS since the data contains nominal and ordinal data.

\subsection{Hypothesis}

Hypothesis 1

Ho: There is no relationship between psychological perception and online database usage.

Ha: There is a relationship between psychological perception and online database usage.

Hypothesis 2

Ho: There is no relationship between searching strategy and online database usage.

Ha: There is a relationship between searching strategy and online database usage.
Hypothesis 3

Ho: There is no relationship between resources and online database usage.

Ha: There is a relationship between resources and online database usage.

In summary, ISB elements which consist of psychological perception, searching strategies and the information resources provided by IIUM library are related to the usage of online database usage among IIUM undergraduate students. As the dependent variable, online database usage is expected to be influenced by psychological perception, searching strategies and the information resources provided by IIUM library.

\section{Methodology}

\subsection{Research design}

There are four main types of design for Quantitative studies which are descriptive, correlational, quasi-experimental and experimental [22]. This study is conducted using correlational study design since the key focus of the study is to observe and explore relationship among variables. Correlational study is another form of nonexperimental research in which the researcher measure and describe the relationship between two or more variables using correlational statistic [23].

Therefore, this correlational study is used to discover the relationship between independent variables (IV) which are 1) searching strategy, 2) student psychological perception and 3) resources, and dependent variable (DV), online database usage.

Moreover, quantitative research is utilized in this study since it is appropriate for a study that tests the hypothesis among numerous constructs [24]. Quantitative data is obtained through the questionnaire developed and distributed to the respondents.

\subsection{Sample design}

Questionnaires are given to the respondents in Center for Foundation Studies in IIUM, Petaling Jaya and main campus, Gombak. The study includes all undergraduate students randomly from all levels of studies, from 1st year to 4th year. In order to determine the suitable sample size calculator, Raosoft.com website is used. The calculator shows 68 respondents are needed out of 15,625 undergraduate students. However, there are 118 respondents gathered in this study.

\subsection{Research instruments}

IBM SPSS is the instrument used for calculating the result to examine the relationship between variables 
Table 2. Demographic information detail

\begin{tabular}{lll}
\hline Section & Number & Research Aspect \\
\hline \multirow{2}{*}{ Part 1: } & 1. & Level of Study \\
Demographic & 2. & Gender \\
information & 3. & Kuliyyah \\
& 4. & Searching Skill Background \\
\hline
\end{tabular}

above. Data collected through the questionnaire developed w ere divided into 2 sections, 1) demographic information and 2) ISB elements. ISB elements contain 1) information searching strategies, 2) psychological perception and 3) resources provided by IIUM Library. The questionnaire was developed and adapted using existing templates from:

- Questionnaire for Alex-San community library user survey (University of South Africa, 2012),

- Electronic resources for library users: a survey by the Washington State Library [25],

- Uw-Sheboygan library services student satisfaction \& usage survey - Spring 2014 [26].

\subsubsection{Questionnaire structure}

The main part of the questionnaire is demographic information where according to Mohammad Daud [28], demographic information can be related to the emotion of the respondent over something. Thus, it may affect the behavior and psychological perception, which also related to personal emotional and mental state of a person. Item in demographic information is listed below in Table 2.

Part 2 consists of the elements of ISB. Questions provided are related to psychological perceptions, information searching strategies and how resources can affect the usage of online database in IIUM. Table 3 shows the questions provided.

There are 27 questions in the questionnaire and most of the questions have been used by previous researchers for their studies. Likert scale and MCQ questions were involved in the questionnaire.

\subsection{Data collection}

Data is collected through questionnaire which is constructed from the variables identified. 118 respondents

Table 3. ISB elements in Part 2

\begin{tabular}{|c|c|c|}
\hline $\begin{array}{l}\text { ISB } \\
\text { elements }\end{array}$ & Number & Research aspect \\
\hline \multirow{5}{*}{ 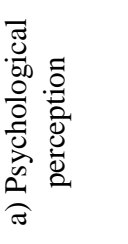 } & 5. & How helpful is online database based on experience \\
\hline & 6. & Does ICT give impact on online database searching \\
\hline & 7. & Consideration to attend training session for online database searching \\
\hline & 8. & The level of confidence to find whatever topic they are looking for in online database \\
\hline & 9. & Difficulty of searching information to complete studies in online database \\
\hline \multirow{9}{*}{ 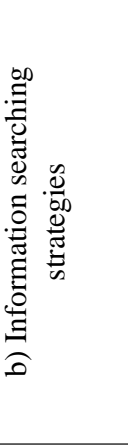 } & 10. & Find resources in other search engine \\
\hline & 11. & Use online database listed provided in library website \\
\hline & 12. & Search using keyword in online database \\
\hline & 13. & Search using subject \\
\hline & 14. & Search using title \\
\hline & 15. & Usually can find the resources needed \\
\hline & 16. & Divert to other method if the first method is unsuccessful \\
\hline & 17. & Use an online database to search academic material \\
\hline & 18. & Usually can find the resources needed \\
\hline \multirow{9}{*}{ 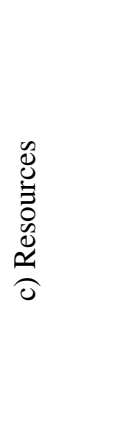 } & 19. & Appropriateness of resources for student course \\
\hline & 20. & List of online database in library website is useful \\
\hline & 21. & The library's website is clear, well-organized, and enables me to easily locate the resources I'm looking for. \\
\hline & 22. & Resources are up to date and relevant \\
\hline & 23. & Resources are easy to find \\
\hline & 24. & You usually find the resources you need \\
\hline & 25. & Report the difficulty of locating resources to the lecturer \\
\hline & 26. & You find there are always resources available that address assignment questions \\
\hline & 27. & Online databases satisfy a variety of information needs \\
\hline
\end{tabular}


from approximately 15,625 undergraduate students answered the questionnaire. Data is gathered manually and online where the questionnaire was created by SurveyMonkey and distributed using social media such as Facebook. All 118 questionnaires (100\%) distributed directly and via online were properly filled and returned. The data is elaborated descriptively and using parametric skills such as mean and standard deviation.

\section{Analysis}

The result is analyzed using IBM SPSS Statistic version 22. Questionnaire answered by the respondents was carefully checked to make sure it is completed. Only the completed form answered by the respondent will be accepted and analyzed. The answers were all inserted in IBM SPSS and analyzed. Later the data analysis will be measured and manipulated using certain formula and numbers using IBM SPSS Statistic version 22 to answer the hypotheses and research questions.

\subsection{Demographic information of undergraduate student in IIUM}

Section 1 consists of question 1 until question 4 designed to determine some important demographic information of respondents that can be useful for the study. Respondents were asked about their level of study, gender, which Kulliyyah did they belong to,

Table 4. Classification of Mean (Daud Johari, 2014)

\begin{tabular}{lc}
\hline Classification & Mean score \\
\hline High & $3.2-4.2$ \\
Medium & $2.1-3.1$ \\
Low & $1.0-2.0$ \\
\hline
\end{tabular}

and their searching skill background. The result of this section is provided in Table 4. It is presented using frequency and percentage resulting from SPSS.

\section{Findings}

Based on the data collection and methodological aspect, the analyzed data will be used in this section to examine the relationship between variables in hypotheses. The section is divided into two sections; one section is to prove and test the hypotheses and the other section is to refine the model of this study according to the finding.

The mean classes will determine the reliability of the variables whether it is low, medium or high. The formula used to categorize the three (low, medium, high) classes of mean range is as below:

$$
3 \text { classes of }=\frac{(\text { Range })-1}{3(\text { Range })}=\frac{3}{3}=1.00 .
$$

The classification of mean according to Daud [28] is as in Table 4.

\subsection{Psychological perception among IIUM undergraduate student}

Table 5 shows $81.4 \%$ of undergraduate students in IIUM are mostly aware and admitted that online database is helpful for them. They also agree that ICT gives impact on information seeking since $94.9 \%$ answered yes.

Total of students who can find the specific titles/ subject areas they are looking for when they check the online databases is medium as according to the range of mean stated earlier, 2.62 is within the medium class. Most of them feel burdened to search information in online database because according to the

Table 5. Question in psychological perception section

\begin{tabular}{llcc}
\hline Dichotomous question & Yes (\%) & No (\%) \\
\hline 5. & $\begin{array}{l}\text { From your experience, do you think online } \\
\text { database is helpful? }\end{array}$ & 81.4 & $\mathbf{1 8 . 6}$ \\
\hline $6 . \quad \begin{array}{l}\text { Do you think ICT gives impact on information } \\
\text { seeking? }\end{array}$ & 94.9 & $\mathbf{5 . 1}$ \\
\hline $7 . \quad \begin{array}{l}\text { You have considered signing up for training } \\
\text { sessions }\end{array}$ & 50.8 & $\mathbf{4 9 . 2}$ \\
\hline 4 and 5 Likert scale & \multicolumn{2}{|c}{ Mean } \\
\hline $8 . \quad \begin{array}{l}\text { You are able to find the specific titles/subject } \\
\text { areas you are looking for when you check the } \\
\text { online databases. }\end{array}$ & \multicolumn{2}{|c}{$\mathbf{2 . 6 2}$} \\
\hline $\begin{array}{l}\text { Online databases are hard to search for } \\
\text { information needed to complete my studies }\end{array}$ & $\mathbf{3 . 3 9}$ \\
\hline
\end{tabular}


Table 6. Question in information searching strategy

\begin{tabular}{|c|c|c|c|}
\hline \multicolumn{2}{|c|}{ Likert question } & \multicolumn{2}{|c|}{ Mean score } \\
\hline 10. & $\begin{array}{l}\text { Suggestions to find resources elsewhere are } \\
\text { good (other search engines e.g; Google, Yahoo) }\end{array}$ & \multicolumn{2}{|c|}{2.71} \\
\hline 11. & $\begin{array}{l}\text { You use any of online databases listed on the } \\
\text { library website }\end{array}$ & \multicolumn{2}{|c|}{2.61} \\
\hline 12. & $\begin{array}{l}\text { When using the online databases, you search } \\
\text { using keyword }\end{array}$ & \multicolumn{2}{|c|}{2.57} \\
\hline 13. & $\begin{array}{l}\text { When using the catalogue, you search using } \\
\text { subject }\end{array}$ & \multicolumn{2}{|c|}{2.42} \\
\hline 14. & When using the catalogue, you search using title & \multicolumn{2}{|c|}{2.77} \\
\hline 15. & $\begin{array}{l}\text { When using the catalogue, you search using } \\
\text { author }\end{array}$ & \multicolumn{2}{|c|}{2.23} \\
\hline 16. & You usually find the resources you need & \multicolumn{2}{|c|}{2.67} \\
\hline 17. & $\begin{array}{l}\text { You use a different method if your first search is } \\
\text { unsuccessful }\end{array}$ & \multicolumn{2}{|c|}{2.86} \\
\hline \multicolumn{2}{|c|}{ Dichotomous question } & Yes $(\%)$ & No $(\%)$ \\
\hline 18. & $\begin{array}{l}\text { You use an online database to search } \\
\text { academic material. }\end{array}$ & 79.7 & 20.3 \\
\hline
\end{tabular}

analysis, mean score is 3.39 and it is in high class of mean score.

Therefore, in this section, it can be concluded that although undergraduate students in IIUM are aware that ICT can help information seeking and online database can be helpful to them, it is still hard to search information they need and not all of them could find the specific title or subject when they search it in online database provided.

\subsection{Information searching strategy among undergraduate student in IIUM}

Table 6 shows the highest mean score is 2.86 where students will use a different method if their first meth- od is unsuccessful. Total mean score for questions 10 to 17 calculated in SPSS stated is 2.37 as stated in Table 6.

Total mean score of 2.37 for questions $10-17$ is categorized in medium class. As a conclusion, information searching strategy among IIUM undergraduate students is medium and they have no specific or fix strategy in searching information. However, they

Table 7. Total mean score for question 10-17

\begin{tabular}{cccc}
\hline & N & Mean & $\begin{array}{c}\text { Std. } \\
\text { deviation }\end{array}$ \\
\hline Total mean score Q 10-17 & 118 & 2.3697 & 0.43712 \\
\hline
\end{tabular}

Table 8. Question in resources section

\begin{tabular}{llc}
\hline 4-Likert question & Mean \\
\hline 19. & Resources are appropriate for my course needs & $\mathbf{2 . 9 4}$ \\
\hline 20. & You find the list of online database is useful & $\mathbf{2 . 6 1}$ \\
\hline 21. & $\begin{array}{l}\text { The library's website is clear, well-organized, and enables me to } \\
\text { easily locate the resources I'm looking for. }\end{array}$ & 2.52 \\
\hline 22. & Resources are up to date and relevant & $\mathbf{2 . 6 4}$ \\
\hline 23. & Resources are easy to find & 2.48 \\
\hline 24. & You usually find the resources you need & $\mathbf{2 . 6 7}$ \\
\hline 25. & $\begin{array}{l}\text { You feedback to the lecturer involved that you are having } \\
\text { difficulty locating resources }\end{array}$ & $\mathbf{2 . 2 9}$ \\
\hline 26. & $\begin{array}{l}\text { You find there are always resources available that address } \\
\text { assignment questions }\end{array}$ & $\mathbf{2 . 4 2}$ \\
\hline 5-Likert question & 3.55 \\
\hline 27. & Online databases satisfy a variety of information needs \\
\hline
\end{tabular}


Table 9. Total mean score for question 19-26

\begin{tabular}{cccc}
\hline & N & Mean & $\begin{array}{c}\text { Std. } \\
\text { deviation }\end{array}$ \\
\hline Total mean score Q 19-26 & 118 & 2.5710 & 0.46210 \\
\hline
\end{tabular}

will use online database in order to search academic material since $79.7 \%$ of respondents answered yes to finding academic material in online database.

\subsection{Resources provided by IIUM library (iv)}

The highest mean score is in question 19 with 2.94 as shown in Table 8. It is categorized in medium mean range class, where the question asked about resources appropriateness for the course need.

The result in Table 5 (Question 6) shows total mean score is 2.57, where it is in medium class range and the students agree that online database satisfy variety of information needs since the mean score for the question is 3.55 and it is in high class of mean range.

As the conclusion in this section, the students are aware and agree that online database satisfy a variety of information needs. However, still some of the students are dissatisfied with the resources provided by IIUM library since the total mean score is just in medium range.
Table 11. Total mean score for online database question

\begin{tabular}{lccc}
\hline & $\mathrm{N}$ & Mean & $\begin{array}{c}\text { Std. } \\
\text { deviation }\end{array}$ \\
\hline $\begin{array}{l}\text { Online database usage total } \\
\text { mean score }\end{array}$ & 118 & 2.5593 & 0.52570 \\
\hline
\end{tabular}

\subsection{Usage of online database (DV)}

Some questions in the survey is addressed to see and identify the usage of online database among IIUM undergraduate students as stated in Table 10.

Total mean score for question 1 to 4 is only 2.5 as shown in Table 11. It is considered as medium range class in mean score classification.

Therefore, it can be concluded that the usage of online database in IIUM among undergraduate students is medium. They will use online database to search academic material since $79.7 \%$ answered yes for this question.

\subsection{Research model validation}

Based on the hypothesis test in previous section, the model can be more specified. Figure 6 above is the original model of the research developed based on previous studies.

Table 10. Question referring to usage of online database

\begin{tabular}{|c|c|c|c|}
\hline \multicolumn{2}{|c|}{ Questionnaire } & \multicolumn{2}{|c|}{ Mean } \\
\hline 1. & $\begin{array}{l}\text { You use any of online databases listed on the } \\
\text { library website }\end{array}$ & \multicolumn{2}{|c|}{2.61} \\
\hline 2. & You find the list of online database is useful & \multicolumn{2}{|c|}{2.61} \\
\hline 3. & Resources are easy to find & \multicolumn{2}{|c|}{2.48} \\
\hline 4. & You usually find the resources you need & \multicolumn{2}{|c|}{2.67} \\
\hline \multirow[t]{2}{*}{5.} & \multirow{2}{*}{$\begin{array}{l}\text { You use online database to search academic } \\
\text { material. }\end{array}$} & Yes (\%) & No $(\%)$ \\
\hline & & 79.7 & 20.3 \\
\hline
\end{tabular}

Table 12. Highest significant for Hypothesis 1

\begin{tabular}{lcc}
\hline Usage on online database & $\begin{array}{l}\text { From your experience, do you } \\
\text { think online database is helpful? }\end{array}$ & $\begin{array}{l}\text { You are able to find the specific titles/ } \\
\text { subject areas you are looking for when } \\
\text { you check the online databases }\end{array}$ \\
\hline $\begin{array}{l}\text { You use online database to search academic } \\
\text { material }\end{array}$ & 0.515 & 0.218 \\
\hline You usually find the resources you need & 0.333 & 0.289 \\
\hline Resources are easy to find & 0.310 & 0.326 \\
\hline $\begin{array}{l}\text { You find the list of online database is useful } \\
\text { You use any of online databases listed on } \\
\text { the library Website }\end{array}$ & 0.257 & 0.414 \\
\hline
\end{tabular}


Table 13. Psychological perception ranking

Psychological perception

1. Ability to find specific title or subject areas

2. Experience using online database

Based on hypothesis test, all three hypotheses have relationship with the usage of online database among IIUM undergraduate students. Hypothesis 1 is regarding the psychological perception and the usage of online database. Questions that have highest significance with online database usage are compared in Table 12.

From Table 12 the question "You are able to find the specific titles/subject areas you are looking for when you check the online databases" has higher total value of significance with online database usage. Therefore, the ability to find specific titles or subject areas in online database should be in the first ranking of psychological perception as shown in Table 13.

Hypothesis 2 is about searching strategies and the usage of online database. Questions that have highest significance with the usage of online database usage are compared as Table 14.

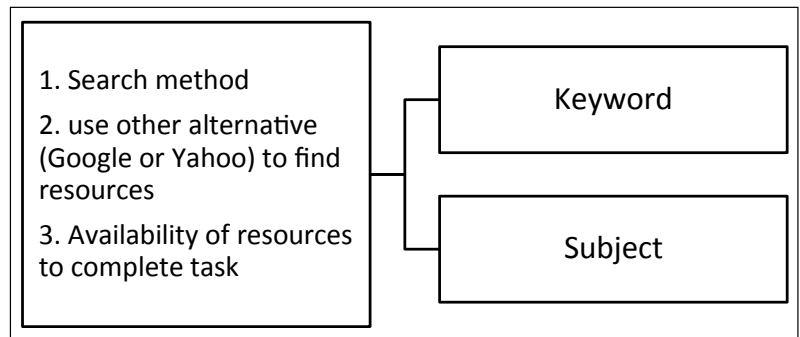

Fig. 7. Specification for resources variable

From Table 14 it can be concluded that searching using keyword has highest total significance compared to search using subject. Students prefer to search in another search engine or alternative such as Google and Yahoo is the third in the list and the last one is the availability of resources for their assignment. Figure 7 is the specification for resources variable.

Hypothesis 3 is to see the relationship between resources and the usage of online database. Questions that have highest significance with the usage of online database usage are compared Table 15.

From Table 15 it appears that resources are up to date, relevant and availability has higher total value of 5significance with online database usage. Therefore, Table 16 is the specification of resources.

Table 14. Highest significant for Hypothesis 2

\begin{tabular}{lcclcc}
\hline & \multicolumn{2}{c}{ Search method comparison } & & \multicolumn{2}{c}{ Others } \\
\cline { 2 - 3 } \cline { 5 - 5 } Usage on online database & $\begin{array}{l}\text { When using catalogue, } \\
\text { you search using } \\
\text { keyword. }\end{array}$ & $\begin{array}{l}\text { When using catalogue, } \\
\text { you search using } \\
\text { subject. }\end{array}$ & & $\begin{array}{l}\text { Suggestions to find } \\
\text { resources elsewhere } \\
\text { are good }\end{array}$ & $\begin{array}{l}\text { Always find resources } \\
\text { available that address } \\
\text { assignment questions }\end{array}$ \\
\hline $\begin{array}{l}\text { You use any of online } \\
\text { databases listed on the } \\
\text { library website }\end{array}$ & 0.490 & 0.468 & 0.468 & 0.313 \\
$\begin{array}{l}\text { You find the list of online } \\
\text { database is useful }\end{array}$ & 0.226 & 0.207 & 0.207 & 0.193 \\
\hline $\begin{array}{l}\text { Resources are easy to find } \\
\text { You usually find the }\end{array}$ & 0.236 & 0.306 & 0.306 & 0.288 \\
\hline \begin{tabular}{l} 
resources you need \\
\hline
\end{tabular} & 0.187 & 0.180 & 0.180 & 0.385 \\
\hline
\end{tabular}

Table 15. Highest significant for Hypothesis 3

\begin{tabular}{|c|c|c|c|}
\hline Usage on online database & $\begin{array}{l}\text { Resources are appropriate } \\
\text { for my course need }\end{array}$ & $\begin{array}{l}\text { Resources are up to date } \\
\text { and relevant }\end{array}$ & $\begin{array}{l}\text { Online database satisfy a } \\
\text { variety of information needs }\end{array}$ \\
\hline $\begin{array}{l}\text { You use online database to search } \\
\text { academic material }\end{array}$ & 0.230 & 0.230 & 0.339 \\
\hline $\begin{array}{l}\text { You usually find the resources you } \\
\text { need }\end{array}$ & 0.333 & 0.333 & 0.288 \\
\hline Resources are easy to find & 0.346 & 0.346 & 0.388 \\
\hline $\begin{array}{l}\text { You find the list of online database } \\
\text { is useful }\end{array}$ & 0.456 & 0.456 & 0.309 \\
\hline $\begin{array}{l}\text { You use any of online databases } \\
\text { listed on the library website }\end{array}$ & 0.208 & 0.208 & 0.206 \\
\hline
\end{tabular}


Table 16. Ranking for resource variable

\begin{tabular}{l}
\hline \multicolumn{1}{c}{ Resources } \\
\hline 1. Availability, latest version and relevant \\
2. Variety of information
\end{tabular}

\subsection{The relationship between ISB and usage of online database}

The relationship between ISB elements and the usage of online database among undergraduate students is determined in correlation test. There are 3 hypotheses in order to examine the relationship, which are:

1 . There is relationship between psychological perception and online database usage.
2. There is relationship between searching strategy and online database usage.

3. There is relationship between resources and online database usage.

All these hypotheses are proven and the null are rejected based on the findings in previous section. In conclusion, the three variables will give influence to the usage of online database among IIUM undergraduate students as represented in ISB model.

\subsection{Relationship between ISB and online database}

The relationship between variables ISB elements and online database usage have been tested using correla-

Table 17. The elements of ISB among IIUM undergraduate student

\begin{tabular}{lll}
\hline & Information seeking behavior elements & \\
\hline \multicolumn{1}{c}{ Psychological perception } & \multicolumn{1}{c}{ Searching strategies } & \multicolumn{1}{c}{ Resources provided } \\
\hline $\begin{array}{l}\text { Ability to find specific title or subject } \\
\text { areas }\end{array}$ & $\begin{array}{l}\text { Search method (using keyword and } \\
\text { subject) }\end{array}$ & $\begin{array}{l}\text { Availability, latest version \& relevant to } \\
\text { course }\end{array}$ \\
Experience using online database & $\begin{array}{l}\text { Use other alternative (Google/Yahoo) to } \\
\text { find resources }\end{array}$ & Information variety \\
& $\begin{array}{l}\text { Availability of resources to complete } \\
\text { task. }\end{array}$ \\
\hline
\end{tabular}

Table 18. Highest significant correlation value between variable

\begin{tabular}{|c|c|c|c|c|}
\hline \multirow{6}{*}{ 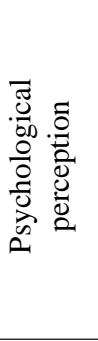 } & \multicolumn{2}{|c|}{$\begin{array}{l}\text { From your experience, do you think online database } \\
\text { is helpful? }\end{array}$} & \multicolumn{2}{|c|}{$\begin{array}{l}\text { You are able to find the specific titles/subject areas you } \\
\text { are looking for when you check the online databases }\end{array}$} \\
\hline & \multicolumn{2}{|c|}{0.515} & \multicolumn{2}{|c|}{0.218} \\
\hline & \multicolumn{2}{|c|}{0.333} & \multicolumn{2}{|c|}{0.289} \\
\hline & \multicolumn{2}{|c|}{0.310} & \multicolumn{2}{|c|}{0.326} \\
\hline & \multicolumn{2}{|c|}{0.257} & \multicolumn{2}{|c|}{0.414} \\
\hline & \multicolumn{2}{|c|}{0.236} & \multicolumn{2}{|c|}{0.537} \\
\hline \multirow{6}{*}{ 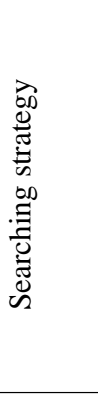 } & \multicolumn{2}{|c|}{ Search method comparison } & \multicolumn{2}{|c|}{ Others } \\
\hline & $\begin{array}{l}\text { When using catalogue, } \\
\text { you search using keyword }\end{array}$ & $\begin{array}{c}\text { When using catalogue, } \\
\text { you search using } \\
\text { subject }\end{array}$ & $\begin{array}{l}\text { Suggestions to find } \\
\text { resources elsewhere are } \\
\text { good }\end{array}$ & $\begin{array}{l}\text { Always find resources } \\
\text { available that address } \\
\text { assignment questions }\end{array}$ \\
\hline & 0.490 & 0.468 & 0.468 & 0.313 \\
\hline & 0.226 & 0.207 & 0.207 & 0.193 \\
\hline & 0.236 & 0.306 & 0.306 & 0.288 \\
\hline & 0.187 & 0.180 & 0.180 & 0.385 \\
\hline \multirow{6}{*}{ 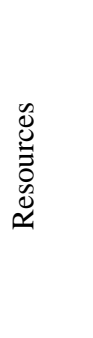 } & $\begin{array}{l}\text { Resources are appropriate } \\
\text { for my course need }\end{array}$ & $\begin{array}{l}\text { Resources are up to } \\
\text { date and relevant }\end{array}$ & \multicolumn{2}{|c|}{$\begin{array}{l}\text { Online database satisfy a variety } \\
\text { of information needs }\end{array}$} \\
\hline & 0.230 & 0.230 & \multicolumn{2}{|c|}{0.339} \\
\hline & 0.333 & 0.333 & \multicolumn{2}{|c|}{0.288} \\
\hline & 0.346 & 0.346 & \multicolumn{2}{|c|}{0.388} \\
\hline & 0.456 & 0.456 & \multicolumn{2}{|c|}{0.309} \\
\hline & 0.208 & 0.208 & \multicolumn{2}{|c|}{0.206} \\
\hline
\end{tabular}




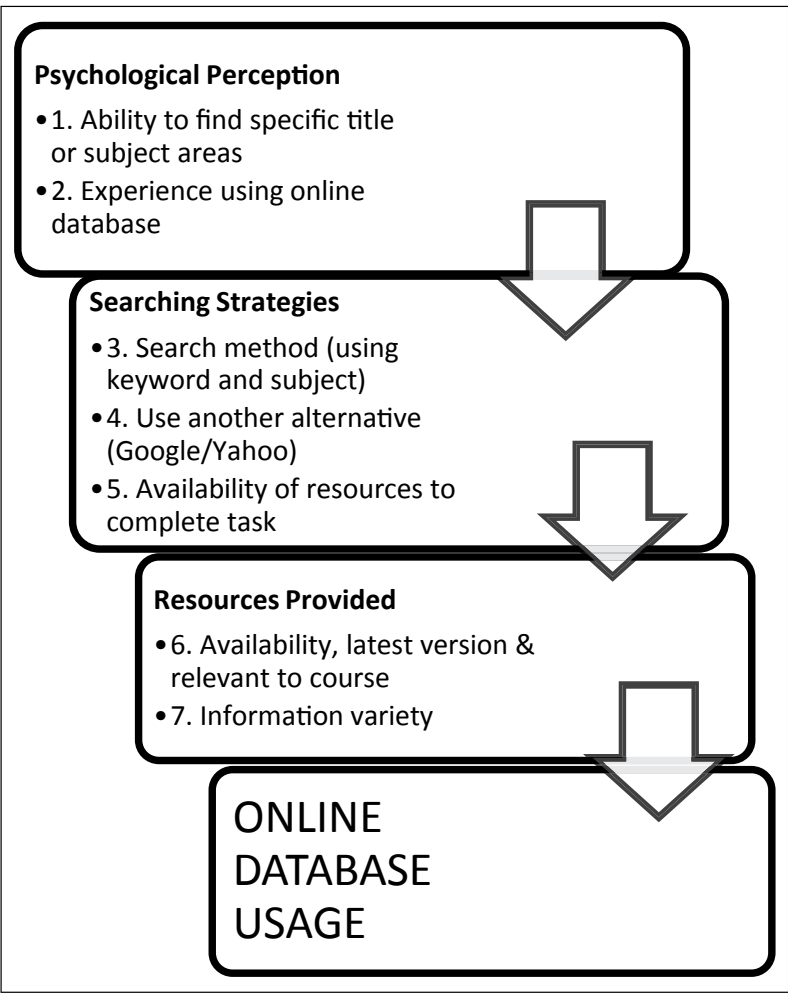

Fig. 8. Refined model of ISB among IIUM undergraduate student

tion test. All significant questions to the usage of online database are listed as below and compared in order to see the highest Pearson correlation value as shown in Table 18.

The result from comparison will be the input and element for ISB model among IIUM undergraduate students.

\subsection{Elements of ISB}

The elements of ISB among IIUM undergraduate students toward the usage of online database are divided into two, which are: external factor and information searching determinant, which come from the students themselves. Elements are listed in ISB model as shown in Table 17.

From the results in Table 18, the model of ISB among undergraduate students is constructed as shown in Fig. 8.

\section{Conclusion}

The outcome of this study concluded that the ISB model can be used by IIUM Library to enhance the usage of online database system subscribed by them. Besides, a search engine can be developed from the model so that the usage can get increased and online databases get fully utilized by the students. The quality of their research and assignment will be higher if they are using authentic resources like provided in the online database.

A future work to improve the interface of the system which can attract the students more can be done also through this research. If the students cannot find resources they want, they can find alternative options to search using other search engines such as Google and Yahoo. Thus, IIUM can design a user-friendly system to the students as well.

The system developer of IIUM IT Division can be guided by ISB model as this research has developed. Besides, the enhancement of related systems and improvement of information retrieval platform can encourage IIUM UG students to take full advantage of the facility and get benefits.

ISB model of IIUM UG students can assist IIUM UG students in solving problems and evaluate the right information they need. Having information literacy skill, IIUM UG students can also expose to the research environment and they will not need to rely solely on notes given or textbook provided. The critical thinking among IIUM UG students can be developed when they know how to retrieve the necessary information independently, from an online database. On the other hand, IIUM UG students will be more aware and alert of the facilities provided by IIUM library and use it adequately.

However, IIUM Library plays an important role in this study since librarians always take an initiative to educate IIUM UG students in demonstrating the techniques of information searching in online database. It is hoped that the ISB model proposed by this study will be beneficial to the librarian in order to recognize IIUM UG students' behavior while instructing them how to use online database. The study also expects that the misunderstanding during teaching and learning between librarians and IIUM UG students will be lower than before. Decision-making for subscribing to online databases will not be an issue anymore as the model can be used for the librarians to assist them to organize IIUM library system interface to place the list of online databases subscribed.

\section{References}

[1] Savolainen R. (2007), Information behavior and information practice: Reviewing the "Umbrella Concepts" of information-seeking studies. The Library Quarterly 77(2), 109-132. http://doi.org/10.1086/517840

[2] Wilson T. D. (2000), Human information behaviour. Informing Science, 3(2), 49-55. Retrieved from http:// inform.nu/Articles/Vol3/v3n2p49-56.pdf

[3] Xie I. (2011), Information Searching and Search Models. In: Encyclopedia of Library and Information Sciences, Third Edition, (August 2013), 2592-2604. http://doi. org/10.1081/E-ELIS3-120043745 
[4] Pal A., Poyen E. F. (2017), Problem solving approach. International Journal of Advanced Engineering Research and Science (IJAERS), 4(5), 184-189.

[5] Hjørland B. (2013), Theories of knowledge organization. Theories of Knowledge Organization, 40(3), 169-182.

[6] Shakeel A., Vinayagamoorthy P. (2013), Information seeking behaviour of business school students : A special study of universities and colleges located in Academic City, Dubai, UAE. Academic Journals, 5(11), 447-456. http:// doi.org/10.5897/IJLIS2013.0402

[7] Malik A. (2009), Web search behavior of university students : A case study at University of the Punjab. Webology, 6(2), 1-14.

[8] Goel S., Yadav S. (2012), An overview of search engine evaluation strategies. International Journal of Applied Information Systems, 1(4), 7-10. http://doi.org/10.5120/ ijais12-450156.

[9] Bhatt A. A. (2014), Information needs, perceptions and quests of law faculty in the digital era. The Electronic Library, 32(5), 659-669. http://doi.org/10.1108/EL-112012-0152

[10] Roy P., Kumar S., Satija M. P. (2012), Problems in searching online databases: A case study of select central university libraries in India. DESIDOC Journal of Library and Information Technology, 32(1), 59-63.

[11] Atilgan D., Bayram O. (2006), An Evaluation of the Use of the Digital Libraries at Ankara University, Turkey, 1-19. Retrieved from http://eprints.rclis.org/7197/

[12] Mbabu L. G., Bertram A., Varnum K. (2013), Patterns of undergraduates' use of scholarly databases in a large research university. The Journal of Academic Librarianship, 39(2), 189-193. http://doi.org/10.1016/j.acalib.2012.10.004

[13] Azoulay-Schwartz R., Ilani Z. (2007), An intelligent tutoring system for efficient usage of databases. ITRE 2006. In: 4th International Conference on Information Technology: Research and Education, Proceedings, pp. 18-22. http:// doi.org/10.1109/ITRE.2006.381524

[14] Bates M. J. (2010), Information behavior. In: Encyclopedia of Library and Information Sciences, pp. 23812391. http://doi.org/doi:10.1081/E-ELIS3-120043263 r10.1081/E-ELIS3-120043263

[15] Yamin F. M., Ramayah T. (2011), User web search behavior on query formulation. In: International Conference on Semantic Technology and Information Retrieval, STAIR 2011, pp. 182-188. http://doi.org/10.1109/ STAIR.2011.5995786
[16] Sriram B. (2016), Factors influencing the internet resource users satisfaction: An analytical study on omani undergraduate learners. Education and Information Technologies, 21, 729-745. http://doi.org/10.1007/s10639-0149351-7

[17] Wilson T. D. (2007), Evolution in information behavior modeling: Wilson's model. Theories of Information Behavior, (Journal Article), 31-36. Retrieved from http://informationr.net/tdw/publ/papers/2005SIGUSE.html

[18] Niu X., Hemminger B. M. (2012), A study of factors that affect the information-seeking behavior of academic scientists. Journal of the American Society for Information Science and Technology, 63(2), 336-353. http://doi. org/10.1002/asi.21669

[19] Wilson T. D. (1966), Models in information behavior research. Journal of Documentation, 22(3), 266-268. http:// doi.org/10.1108/eb026404

[20] Wilson T. D. (1999), Models in information behavior research. Journal of Documentation, 55(3), 249-270. http:// doi.org/10.1108/EUM0000000007145

[21] Simon M. K., Goes J. (2011), Developing a Theoretical Framework. Dissertation recepies. http://doi. org/10.1186/1472-6963-11-23

[22] Bacon-Shone J. (2015), Introduction to Quantitative Research Methods. Graduate School, The University of Hong Kong. http://doi.org/10.13140/2.1.4466.3040.

[23] Creswell J. W. (2012), Research Design: Qualitative, Quantitative and Mixed Method Approaches. (Knight V., Young J., Koscielak K., (eds.) (2014), 4th ed. United Kingdom: SAGE Publications. Department of Information Science \& University of South Africa. Practical Portfolio User Surveys

[24] Subramaniam A., Silong A. D., Uli J., Ismail I. A. (2015), Effects of coaching supervision, mentoring supervision and abusive supervision on talent development among trainee doctors in public hospitals: moderating role of clinical learning environment. BMC Medical Education, 15, 129. http://doi.org/10.1186/s12909-015-0407-1

[25] Ferrari A. (2011), Electronic Resources for Library Users: A Survey by the Washington State Library. Washington State.

[26] UW-Sheboygan Library Services (2014), UW-Sheboygan Library Services Student Satisfaction \& Usage Survey.

[27] Daud J. M. (2014), Morel dan Pengaruhnya Terhadap Motivasi dan Komitmen Dalam Kalangan Anggota Tentera Darat Malaysia. 